\title{
What makes astronomical heritage valuable? Identifying potential Outstanding Universal Value in cultural properties relating to astronomy
}

\author{
Michel Cotte C $^{1,2}$ \\ ${ }^{1}$ World Heritage Unit, ICOMOS, Tournon, France \\ ${ }^{2}$ Centre François Viète d'histoire des sciences et des techniques, \\ University of Nantes, Nantes, France \\ email: cotte.michel@orange.fr
}

\begin{abstract}
This communication presents the situation regarding astronomical and archaeoastronomical heritage related to the World Heritage Convention through recent years up until today. Some parallel events and works were promoted strongly within the IAU-UNESCO Initiative during the International Year of Astronomy (2009). This was followed by a joint program by the IAU and ICOMOS - an official advisory body assisting the World Heritage Committee in the evaluation of nomination dossiers. The result of that work is an important publication by around 40 authors from 20 different countries all around the world: Heritage Sites of Astronomy and Archaeoastronomy in the Context of the UNESCO World Heritage Convention (Ruggles \& Cotte 2010). A second volume is under preparation (2015). It was also accompanied by some initiatives such as the "Windows to the Universe" organisation and the parallel constitution of local "Starlight Reserves". Some regional meetings studying specific facets or regional heritage in the field giving significant knowledge progresses also accompanied the global trend for astronomical heritage.

WH assessment is defined by a relatively strict format and methodology. A key phrase is "demonstration of Outstanding Universal Value" to justify the WH Listing by the Committee. This communication first examines the requirements and evaluation practices about of demonstrating OUV for a given place in the context of astronomical or archaeoastronomical heritage. That means the examination of the tangible attributes, an inventory of the property in terms of immoveable and moveable components and an inventory of intangible issues related to the history (history of the place in the context of the history of astronomy and cultural history). This is also related to the application to the site of the concept of integrity and authenticity, as regards the place itself and in comparison with other similar places (WH sites already listed, sites on national WH Tentative Lists, or other similar places in the region). The second issue of the communication is to give a glimpse of today's WH List, including some difficulties with listing and occasional failures, and trends and promising approaches.
\end{abstract}

Keywords. Astronomical heritage, Archaeoastronomical heritage, Outstanding Universal Value (OUV)

\section{Introduction: New themes for the World Heritage List?}

Since the 1990s, the "Global strategy for a representative, balanced and credible World Heritage List" has extended the scope of the WH Convention beyond the classical fields studied since its inception (UNESCO 1972). The new fields include: 
- Canals, corridors of transportation;

- Cultural roads;

- Industrial heritage; and

- Heritage of technology and sciences.

Examples of listed properties include the Cultural road of Camino Real (Mexico), the industrial site of saltpeter works at Humberstone and Santa Laura (Chile), and the mountain railway of India (serial nomination, India).

There are also two new trans-thematic methods for a broader implementation of the WH Convention:

- Cultural landscapes; and

- The possibility of serial nominations (with national or trans-national boundaries). These have permitted, for example, the inscription of the Grand Canal (China), Rice terraces (Phillippines), and Qhapaq Nan, the Andean road system (6 states).

Nevertheless, such enlargement must be done in a common format for all the past and new categories of the WH List, for both natural and cultural properties, as is stated in the official Guidelines (UNESCO 2015).

\section{The ICOMOS-IAU joint Thematic Study}

At the end of the 2000s, the joint Initiative for Astronomy by UNESCO and the International Astronomical Union underlined the importance of astronomical and archaeoastronomical heritage. It also demonstrated the need to develop case studies for tangible evidence and related intangible values, and the need for an interdisciplinary methodology for heritage analysis both in scientific and heritage terms.

The initial question was: "What are the best ways to support and encourage the recognition of the most outstanding examples of astronomical heritage?". The best answer could be the World Heritage List. The methodology and case studies must accord with the WH Guidelines and recommendations. The natural partners become ICOMOS for cultural heritage and the IUCN for natural heritage.

Regarding methodology, the subject of astronomical and archaeoastronomical heritage appears as a specific multidisciplinary field, merging architecture, archaeology, sociology, technology and science. This complex heritage needs global overviews of subfields (periods, regions?), well understood and well analyzed case studies, and inventories and comparisons. All this assumes a shift from enthusiasm to professionalism.

The ICOMOS-IAU joint Thematic Study on the Heritage of Astronomy and Archaeoastronomy (vol. 1) was achieved in 2010 (Ruggles \& Cotte (2010)). The list of themes aims to provide a short and clear overview of the recognized evidence relating to astronomical heritage in general, from prehistoric times to 20th-century heritage, and for every part of the world through historical times.

Contributions involved more than 40 authors from some 20 different countries from all regions of the world. The result is 16 chapters following chronology and geography with a consistent introductioon and conclusion by the editors highlighting epistemological and methodological questions. This Thematic Study, a tool for a first valuable approach, is freely available on-line (www.astronomicalheritage.net/index.php/about/astronomyand-world-heritage/icomos-iau-thematic-study).

\section{WH recognition for astronomical and archaeoastronomical heritage}

Few sites are recognized for their astronomical values alone, but some, such as the Struve Arc (serial nomination, Europe) and Jantar Mantar at Jaipur (India), are 


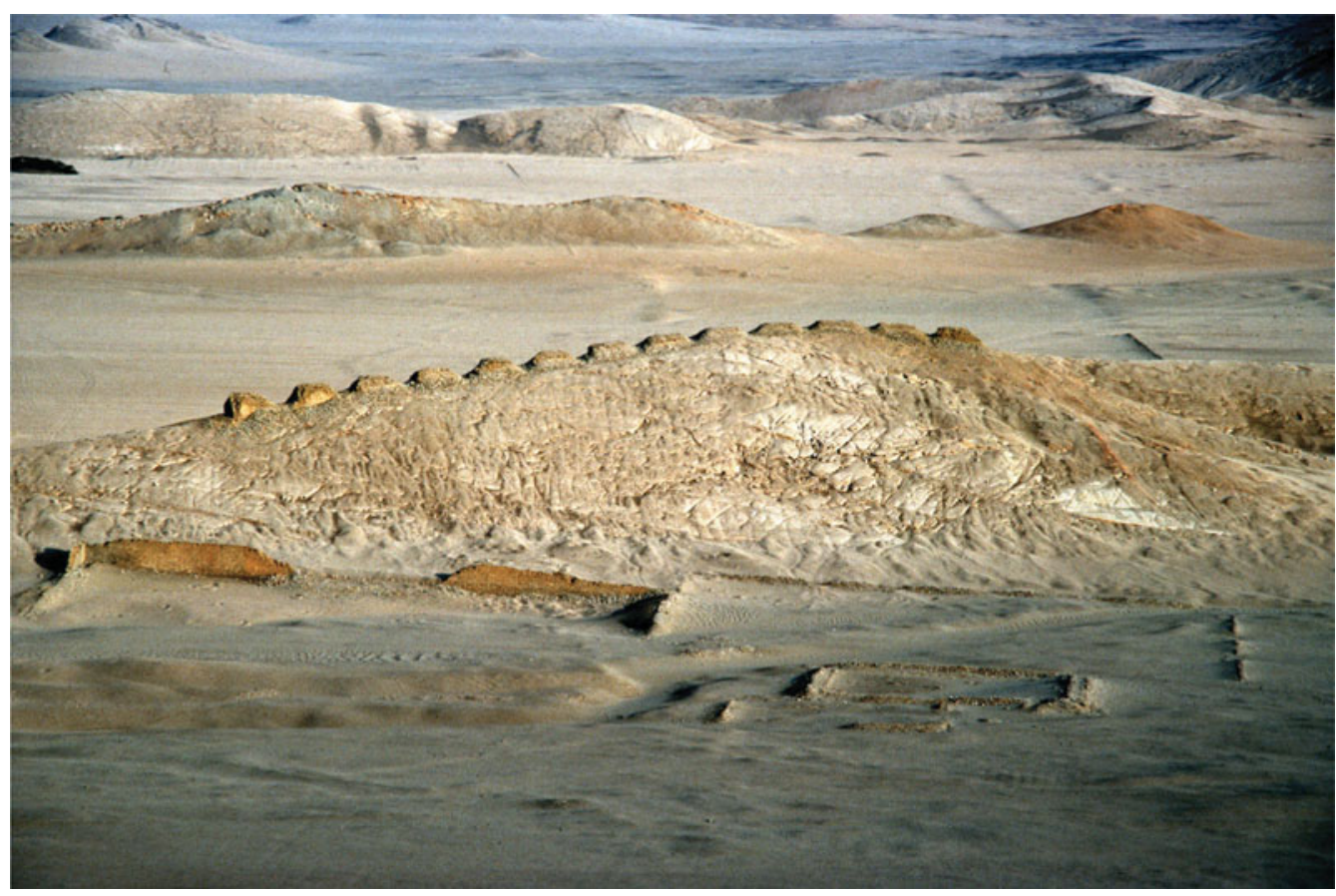

Figure 1. The Thirteen Towers as seen from the Fortress. CCIván Ghezzi

already inscribed on the WH List. Some important places are listed with their important associated value for astronomy or archaeoastronomy being recognized. These include Samarkand (central Asia), Denfeng (China), various places in Egypt and pre-Columbian Mesoamerica, Stonehenge (UK), etc.

Since 2010 we have pursued and deepened the Thematic Study with "Extended case Studies" published on the UNESCO-IAU Portal to the Heritage of Astronomy (www.astronomicalheritage.net). A number of sites have appeared on national "Tentative Lists". A second volume of the Thematic Study will be submitted to ICOMOS for peer review in order to be published as an official document of the WH Committee.

These include some rare but extremely important archaeoastronomical individual cases. A paradigmatic example is certainly Chankillo in Peru (Fig. 1), but there are others.

Frequently, the astronomical value of already WH-listed places is not really recognized; we have to encourage State Parties to refurbish it correctly during the process of OUV revision. A case in point is Pulkovo Observatory, St Petersburg, Russia.

Many examples of astronomical heritage are members of important subcategories along with similar sites. This encourages serial approaches and strict selection. One of the most promising possible series is the "High-mountain observatories" which merge various qualities: precise definition of the series, global repartition, merging with dark sky reserve initiative, outstanding contribution to the scientific understanding of the Universe, etc.

\section{Conclusion: Astronomical and archaeoastronomical heritage in context}

Astronomy can take many forms but it is never alone: it is always a part of a larger ensemble of attributes that characterize a human society at a given time. Astronomy was permanently not only "pure" knowledge but an important part of human symbolic 
representations (cosmology). Consequently, the study of astronomical and archaeoastronomical heritage is a multidisciplinary field and the efforts made in this manner by the Thematic Studies is promising.

Although the World Heritage Convention focuses on "tangible immoveable heritage", we have to present immovable as well as moveable, and intangible as well as tangible; only the global approach make sense and indicates the real value of the place. The core of scientific knowledge is mainly intangible. It is an intellectual framework of the human spirit using specialized languages (written language, mathematics, etc.) and images (drawings, maps, photographs, physical information such as spectra, and so on).

The distinction between property and moveable objects is important from the juridical and heritage perspective, but has no real significance for astronomers. Archives, collections and bibliographies are hugely important. These documents are the product of scientific activities in their cultural context. The only reasonable conclusion is that the dichotomy between "fixed" and "moveable" makes little sense as a classificatory criterion in astronomical heritage in particular, or in science or technology heritage in general.

Regarding cultural and natural heritage relating to astronomy, one importance of natural and cultural landscapes (e.g. the High-mountain observatories) is that they provide a possible way for the recognition of the "Dark Sky" quality of a place among other attiributes. Astronomy represents a rich and significant aspect of cultural and natural heritage. Recognizing this permits us to identify and to clarify astronomical value in the context of the World Heritage Convention.

\section{References}

Ruggles, C. \& Cotte, M. (eds.) 2010, Heritage Sites of Astronomy and Archaeoastronomy in the context of the UNESCO World Heritage Convention (Paris: ICOMOS -IAU)

UNESCO 1972, Convention concerning the protection of the World Cultural and Natural Heritage (Paris: UNESCO) http://whc.unesco.org/en/conventiontext

UNESCO 2015, The Operational Guidelines for the Implementation of the World Heritage Convention (Paris: UNESCO) http://whc.unesco.org/en/guidelines 